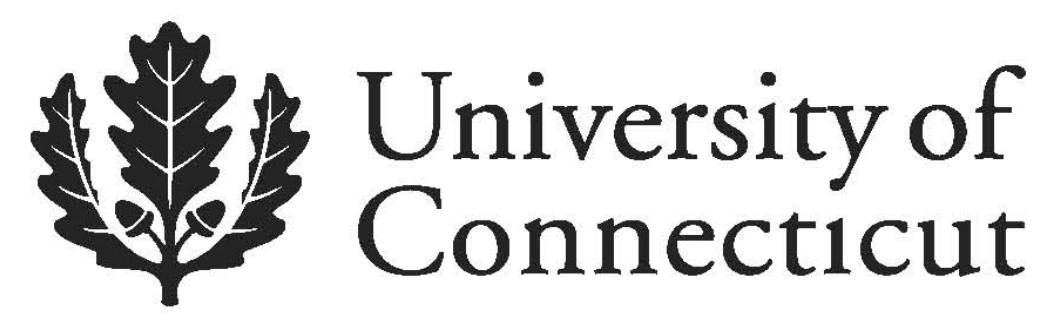

Department of Economics Working Paper Series

Time-Varying Effects of Housing and Stock Prices on U.S. Consumption

Beatrice D. Simo-Kengne

University of Pretoria

Stephen M. Miller

University of Nevada, Las Vegas

University of Connecticut

Rangan Gupta

University of Pretoria

Goodness C. Aye

University of Pretoria

Working Paper 2013-13

June 2013

365 Fairfield Way, Unit 1063

Storrs, CT 06269-1063

Phone: (860) 486-3022

Fax: (860) 486-4463

http://www.econ.uconn.edu/

This working paper is indexed on RePEc, http://repec.org 


\title{
Time-Varying Effects of Housing and Stock Prices on U.S. Consumption
}

\author{
Beatrice D. Simo-Kengne*, Stephen M. Miller**, Rangan Gupta*, and Goodness C. Aye*,
}

\begin{abstract}
This paper applies a time-varying parameter vector autoregressive (TVP-VAR) approach to estimate the relative effects of housing and stock prices on US consumption over time. We use annual data from 1890 to 2012 and find that over different horizons and over time, generally the housing price positively affects consumption while the stock price negatively affects consumption. These opposite responses to changes in housing and stock prices suggest different mechanisms through which wealth affects consumption. Further, the housing price effect proves larger in absolute value than the stock price effect after 1980. Between 1980 and 2007, housing wealth generally exerted a larger effect on consumption. This sub-period includes the 1997/2002 asset price boom/bust where house prices continued to rise moderately as stock prices fell. Finally, the co-occurrence of the decline in both housing and stock prices during the 2007-2009 episode produced bigger effects of the housing price for the first five years of the impulse responses while the higher magnitude of the stock price effect appears in the 6-year horizon. These findings suggest that the magnitude of the relative price effects differs with both time and horizons and also depends on whether prices increase or decrease.
\end{abstract}

Keywords: $\quad$ Asset Prices, Consumption, TVP-VAR

JEL Classification: C32, E21, G10

* Department of Economics, University of Pretoria, Pretoria, 0002, SOUTH AFRICA.

** Corresponding author. Department of Economics, University of Nevada, Las Vegas, Las Vegas, Nevada, 89154-6005, USA. Email: stephen.miller@unlv.edu. 


\section{Introduction}

The housing and stock markets comprise the two major sources of US household wealth. The stock market accounts for about 25 percent of the total net worth (Poterba, 2000) while housing represents approximately 40 percent of households' assets and just under 50 percent of total wealth (Iacoviello, 2011). These two markets experienced big swings in the last decades culminating in the 2007 "Great Recession”. Similar to the Great Depression, which begun with the crash of the stock market, the recent turmoil began with the bust of the subprime mortgage market and the collapse of the housing price bubble. The concomitant decline in consumption reflects, in part, the wealth effect on household spending. The wealth effect characterises the mechanism through which asset price fluctuations may affect financial and business cycles dynamics, making it crucial for policymakers in charge of macroeconomic and financial stability.

This paper considers how US consumption responds dynamically to both housing and stock market prices and how these relationships evolved over time. Examining changes in asset price effects across time may provide further insight on the sources of different responses of consumption to wealth, which proves crucial to policy makers and macroeconomic policy. Using over 120 years of annual data that includes the Great Depression and the Great Recession, this paper implements a TVP-VAR model that captures the potential time-varying structure in the estimation of asset price effects. Figure 1 plots the growth rate of per capita consumption in the US, showing significant volatilities during the twelve decades of the sample period and, thus, implying the possibility of distinct changes in asset price effects over time.

The life cycle and permanent income hypotheses suggest that as financial or housing assets grow, households will more likely increase their consumption spending. Likewise, consumption will decrease as household wealth declines. Since consumption comprises such a 
large share of real GDP, the effects of house and stock prices on consumption through the wealth effect serve as a key link between the asset market and economic activity. Therefore, the dynamics of housing and stock prices and their effects on consumption can importantly affect policy choices as policy makers address asset market and, hence, macroeconomic instability. Conventional macroeconomic models, however, do not provide a clear answer as to whether the propensity to consume out of financial wealth exceeds or falls below that of non financial wealth.

Alternative conceptual rationales generate differences in the consumption effect of changes in the value of different wealth categories, especially housing and stock market wealth. On the one hand, some researchers argue that stock market wealth should exert a bigger effect on consumption than housing wealth. For example, noting that most homeowners live in the houses they own, Aoki et al. (2004) suggest that an increase in house prices raises the opportunity cost of housing services, which directly outweighs the benefits of the induced wealth. Similarly, Poterba (2000) argues that housing price fluctuations induce smaller consumption changes than stock market dynamics due to housing related transaction costs. Furthermore, Mishkin (2007) notes that older people, who hold a larger share of stock wealth, exhibit a high marginal propensity to consume out of wealth. Therefore, the effect of positive housing price shocks on aggregate consumption probably falls below the effect of positive shocks to stock prices, which, in contrast, tend to shift directly the aggregate budget constraint upwards.

On the other hand, other researchers argue that the consumption response to changes in housing wealth exceeds that generated by stock wealth. For example, the relative distributions of housing and stock market wealth may play an important role. Mishkin (2007) suggests that unlike housing wealth, which is generally spread more evenly over the population, stock market wealth concentrates amongst wealthy households (Brady and Stimel, 2011). The resulting highly 
skewed distribution of stock ownership generates a smaller equity wealth effect for most households (Poterba, 2000). Furthermore, during economic expansions with consumer confidence rising, Aoki et al. (2004) argue that homeowners probably borrow to finance consumption and housing investment, since housing represents secured collateral. For the US, Wilkerson and Williams (2011) note that the limited use of stock market wealth for consumption may reflect capital gains taxes on stocks as well as the inaccessibility, except at a cost, of a sizeable share of stock wealth held in restricted retirement or pension accounts. That is, Benjamin et al. (2004) note that for many households, they hold financial wealth indirectly through pensions and insurance. Moreover, tax policy favours home ownership and the concentration of wealth in homes. Thus, an increase in the housing price exerts more of an effect on aggregate consumption than stock market wealth, since housing transactions correlate with complementary consumption goods such as furniture, appliances, and so on. Conversely, besides the permanent nature of capital gains from housing wealth, Lettau and Ludvigson (2004) argue that transitory movements dominate stock market wealth changes and consumption responds much less to transitory than permanent movements in wealth. Finally, US tax laws favours holding housing debt, making housing equity more accessible than other forms of assets.

Empirically, numerous studies document significant and positive wealth effects on US consumption, with a large consensus that the housing wealth effect exceeds that coming from stock market wealth (e.g., Benjamin et al., 2004; Case et al., 2005; Carrol et al., 2006; Dvornak and Kohler, 2007; Kishor, 2007; amongst others). Sousa (2008) points out, however, that the magnitude of the wealth effect depends not only on the wealth measures, but also on the econometric methodologies employed in the analysis. Much of the existing evidence comes from cointegration regressions, which remain questionable (e.g., Carroll et al. 2006). The 
cointegration approach implicitly presumes the existence of a stable long-run relationship between consumption, labour income, and wealth, which proves counterintuitive given the presence of structural changes in the economy. Moreover, the wealth effects from housing and stock market wealth may alter their relative positions depending on whether wealth falls or rises (Wilkerson and Williams, 2011). For example, Leonard (2010) finds that the US housing wealth effect exceeds the stock market wealth effect in absolute value after 2005 than the years before, suggesting that pessimistic households during the housing bust produced a larger decrease in consumption than the induced increase during the boom years.

More importantly, wealth changes may exert a positive or negative effect on consumption depending on the relevant transmission mechanism. Ludwig and Sløk (2001) identify four and five different channels of influence for stock and housing prices, respectively: First, the realised wealth effect implies that an increase in house (stock) prices exerts a direct positive effect on homeowners' (stockholders') consumption as a consequence of the realised gain. Second, the unrealised wealth effect refers to the increase in consumption spending based on the expectation that raising current the housing (stock) price will result in higher future income and wealth. Third, the liquidity constraint effect implies that increasing housing (stock) prices raise the value of collateral against which financially constraint households may borrow to increase their consumption. Fourth, the stock option value effect, specific to stock market, implies that an increase in stock prices leads to the increase in the value of stockholders options which may translate into higher consumption irrespective of whether the gains are realised or unrealised. This differs from the budget constraint effect applicable to the housing market. For this channel, an increase in house prices negatively affects renters' consumption as a result of tighther budget constraint due to the realised capital loss. Finally, the substitution effect associates an increase in 
housing prices to further saving to finance larger downpayments for potential home buyers, which, in turn, lowers consumption.

The first four channels imply that stock prices should exert positive effects on consumption. For housing price changes, however, the budget constraint and substitution effects suggest a negative effect on consumption. We find, however, that over different horizons and over time, generally the housing price positively affects consumption while the stock price negatively affects consumption. These opposite responses to changes in housing and stock prices suggest different mechanisms through which wealth affects consumption. Further, the housing price effect proves larger in absolute value than the stock price effect after 1980. Between 1980 and 2007, housing wealth generally exerted a larger effect on consumption.

We organize the rest of the paper as follows. Section 2 presents the empirical methodology. Section 3 describes the data and discusses the estimation results. Section 4 concludes.

\section{Empirical methodology}

Primiceri (2005) developed the TVP-VAR model, which is now widely used in macroeconometric analysis. Its flexibility and robustness capture the time-varying properties underlying the structure of the economy. Further, Nakajima (2011) notes that the TVP-VAR model with constant volatility probably produces biased estimates due to a potential variation of the volatility in disturbances; thus emphasizing the role of stochastic volatility. The TVP-VAR model with stochastic volatility avoids this misspecification issue by taking care of simultaneous relations among variables as well as the heteroskedasticity of the innovations. This gain in flexibility comes at the expense of a more complicated structure. Therefore, the estimation of the model requires using Markov-Chain Monte-Carlo (MCMC) methods with Bayesian inference. 
The TVP-VAR model emerges from the basic structural VAR model defined as follows:

$$
A y_{t}=F_{1} y_{t-1}+\ldots+F_{s} y_{t-s}+u_{t} \quad t=s+1, \ldots, n
$$

where $y_{t}$ denotes a $k \times 1$ vector of observed variables, and $A, F_{1}, \ldots, F_{s}$ denote $k \times k$ matrices of coefficients. The disturbances $u_{t}$ is a $k \times 1$ structural shock assumed to follow a normal distribution of the form $u_{t} \sim N(O, \Sigma)$, where

$$
\Sigma=\left(\begin{array}{cccc}
\sigma_{1} & 0 & \cdots & 0 \\
0 & \ddots & \ddots & \vdots \\
\vdots & \ddots & \ddots & 0 \\
0 & \cdots & 0 & \sigma_{k}
\end{array}\right) .
$$

To specify the simultaneous relations of the structural shock by recursive identification, A takes on a lower-triangular structure as follows:,

$$
A=\left(\begin{array}{cccc}
1 & 0 & \cdots & 0 \\
a_{21} & \ddots & \ddots & \vdots \\
\vdots & \ddots & \ddots & 0 \\
a_{2 k} & \cdots & a_{k, k-1} & 1
\end{array}\right) .
$$

The model in Equation (1) solves for the following reduced form specification

$$
y_{t}=B_{1} y_{t-1}+\ldots+B_{s} y_{t-s}+A^{-1} \Sigma \varepsilon_{t}, \quad \varepsilon_{t} \sim N\left(0, I_{k}\right)
$$

where $B_{i}=A^{-1} F_{i}$ for $i=1, \ldots, s$. Stacking the elements in the rows of the $B_{i}^{\prime} s$ to form $\beta$ ( $k^{2} s \times 1$ vector), and defining $X_{t}=I_{k} \otimes\left(y_{t-1}^{\prime}, \ldots, y_{t-s}^{\prime}\right)$, where $\otimes$ denotes the Kronecker product, we can rewrite the model as follows:

$$
y_{t}=X_{t} \beta+A^{-1} \Sigma \varepsilon_{t}
$$

All parameters in Equation (5) are time-invariant. By allowing the parameters to change 
over time, Equation (5) further extends to the following specification: ${ }^{1}$

$$
y_{t}=X_{t} \beta_{t}+A_{t}^{-1} \Sigma_{t} \varepsilon_{t}, t=s+1, \ldots, n,
$$

where the coefficients $\beta_{t}$, and the parameters $A_{t}$ and $\Sigma_{t}$ are all time varying. To model the process for these time-varying parameters, Primiceri (2005) assumes the parameters in equation (6) follow a random walk process. Let $a_{t}=\left(a_{21}, a_{31}, a_{32}, a_{41}, \ldots, a_{k, k-1}\right)^{\prime}$ denote a stacked vector of the lower-triangular elements in $A_{t}$ and $h_{t}=\left(h_{1 t}, \ldots, h_{k t}\right)^{\prime}$ with $h_{j t}=\log \sigma_{j t}^{2}$ for $j=1, \ldots, k$, $t=s+1, \ldots, n$. Thus,

$$
\begin{aligned}
& \beta_{t+1}=\beta_{t}+u_{\beta_{t}}, \\
& a_{t+1}=a_{t}+u_{a_{t}}, \\
& h_{t+1}=h_{t}+u_{h_{t}},
\end{aligned} \quad \quad \quad \quad\left(\begin{array}{c}
\varepsilon_{t} \\
u_{\beta_{t}} \\
u_{a_{t}} \\
u_{h_{t}}
\end{array}\right) \sim N\left(0,\left(\begin{array}{cccc}
I & 0 & 0 & 0 \\
0 & \Sigma_{\beta} & 0 & 0 \\
0 & 0 & \Sigma_{a} & 0 \\
0 & 0 & 0 & \Sigma_{h}
\end{array}\right)\right)
$$

for $t=s+1, \ldots, n$, where $\beta_{s+1} \sim N\left(\mu_{\beta_{0}}, \Sigma_{\beta_{0}}\right), a_{s+1} \sim N\left(\mu_{a_{0}}, \Sigma_{a_{0}}\right)$ and $h_{s+1} \sim N\left(\mu_{h_{0}}, \Sigma_{h_{0}}\right)$.

This methodology exploits the salient feature of the VAR model with time-varying coefficients to estimate a three variable VAR model (consumption, the housing price, and the stock market price), focusing on the dynamics of the wealth effects from both house and stock price adjustments. By allowing all parameters to vary over time, this paper examines the assumption of parameter constancy for the VAR's structural shocks based on the standard recursive identification procedure known as the Choleski decomposition. We achieve identification by imposing a lower triangular representation on the matrix $A_{t}$. The recursive ordering of the variables that proves consistent with the VAR based empirical literature on

\footnotetext{
${ }^{1}$ See Nakajima (2011) and Pimiceri (2005) for further details on the TVP-VAR methodology.
} 
wealth effects of consumption. ${ }^{2}$ That is, consumption comes first in the ordering and it does not respond contemporaneously to housing and stock market price (wealth) shocks, while house prices react with a lag to stock market price shocks. Thus, the housing price appears second in the ordering before the stock market price.

\section{Data and results}

\subsection{Data}

To examine the time-varying structure of wealth effects, we estimate the three-variable TVPVAR model using annual data from 1890 to 2012. The dataset comes primarily from the Online Data section of Robert Shiller's website ${ }^{3}$ and includes real per capita consumption, the real stock market price, and the real housing price. The data series on these variables however, only run to 2009 on Robert Shiller's website. We update the data through 2012, using the definition of the variables and sources outlined in the data files of Robert Shiller. We transform all variables in their log-differenced form to ensure stationarity, given the existence of unit root in their level forms. ${ }^{4}$ We define the growth rates of consumption, the real housing price, and the real stock price as $C, R H P$, and $R S P$, respectively. For ease of comparison and interpretation, we standardize the stock market and housing prices series using the standard deviation. We choose a lag length of two based on the Akaike information criteria applied to a stable constant parameter

\footnotetext{
${ }^{2}$ See Aye et al., (forthcoming) for a detailed discussion in this regard.

${ }^{3}$ http://www.econ.yale.edu/ shiller/data.htm.

${ }^{4}$ We use standard unit-root tests, namely, Augmented Dickey and Fuller (ADF)(1981), Phillips and Perron (PP) (1988), Dickey and Fuller with Generalised Least Squares detrending (DF-GLS), and the Ng and Perron (2001) modified version of the PP (NP-MZt) to confirm that the log-levels of the three variables under consideration are integrated of order 1, i.e., I(1). Given nonstationary data, we also conducted the Johansen $(1988,1991)$ tests of cointegration. Both the Trace and Maximum Eigenvalue tests, however, do not reject the null of no cointegration, which, in turn, implies that our VAR in first differences does not need to account for error correction, and hence, is not misspecified. The unit-root and cointegration tests are available on request from the authors.
} 
VAR. ${ }^{5}$ Since we convert the variables into their growth rates and use two lags, the effective sample of our analysis starts in 1894.

\subsection{Estimation results}

Table 1 reports the posterior estimates computed using MCMC algorithm based on keeping 100,000 draws after 10,000 burn-ins. ${ }^{6}$ Figure 2 presents the estimation results on the TVP-VAR model with stochastic volatility. We perform diagnostic tests for convergence and efficiency. The 95-percent credible intervals include the estimates of the posterior means and the convergence diagnostic (CD) statistics developed by Geweke (1992). ${ }^{7}$ We cannot reject the null hypothesis of convergence to the posterior distribution at the conventional level of significance. In addition, we also observe low inefficiency factors, confirming the efficiency of the MCMC algorithm in replicating the posterior draws.

\subsubsection{Estimates of the stochastic volatility}

Figure 1 plots the posterior draws for each time series (top graphs) and the posterior estimates of the stochastic volatility (bottom graphs). The results indicate that per capita consumption growth

\footnotetext{
${ }^{5}$ We find that all roots of the constant parameter VAR lie within the unit circle, implying stability.

${ }^{6}$ The MCMC method assesses the joint posterior distributions of the parameters of interest based on certain prior probability densities that are set in advance. This paper adopts the following priors as found in Nakajima (2011): $\Sigma_{\beta} \sim I W(25,0.01 I),\left(\Sigma_{a}\right)_{i}^{-2} \sim G(4,0.02),\left(\Sigma_{h}\right)_{i}^{-2} \sim G(4,0.02)$, where $\left(\Sigma_{a}\right)_{i}^{-2}$ and $\left(\Sigma_{h}\right)_{i}^{-2}$ are the $i^{\text {th }}$ diagonal of elements of $\Sigma_{a}$ and $\Sigma_{h}$, respectively. IW and G denote the inverse Wishart and the Gamma distributions, respectively. We use flat priors to set initial values of time-varying parameters such that: $\mu_{\beta_{0}}=\mu_{a_{0}}=\mu_{h_{0}}=0$ and $\Sigma_{\beta_{0}}=\Sigma_{a_{0}}=\Sigma_{h_{0}}=10 \times I$.

${ }^{7}$ Geweke (1992) suggests comparing the first $n_{0}$ draws to the last $n_{1}$ draws, dropping out the middle draws, to check for convergence in the Markov chain. The CD statistics are computed as follows: $C D=\left(\bar{x}_{0}-\bar{x}_{1}\right) / \sqrt{\hat{\sigma}_{0}^{2} / n_{0}+\hat{\sigma}_{1}^{2} / n_{1}}$, where $\bar{x}_{j}=\left(1 / n_{j}\right) \sum_{i=m_{j}}^{m_{j}+n_{j}-1} x^{(i)}$, where $x^{(i)}$ is the $i^{\text {th }}$ draw, and $\hat{\sigma}_{j}^{2} / n_{j}$ is the standard error of $\bar{x}_{j}$ respectively for $j=0$, 1. If the sequence of the MCMC sampling is stationary, it converges to a standard normal distribution. We set $m_{0}=1$, $n_{0}=10000, m_{1}=50001$, and $n_{1}=50000 . \hat{\sigma}_{j}^{2}$ is computed using a Prazen window with bandwidth $\left(B_{m}\right)=500$. The inefficiency factor is defined as $1+2 \sum_{s=1}^{B_{m}} \rho_{s}$, where $\rho_{s}$ is the sample autocorrelation at lag $s$, which is computed to measure how well the MCMC chain mixes.
} 
volatility peaks at the beginning of the sample followed by a downward trend thereafter. The volatility stabilized at a low level in the early 1970s, which includes the Great Moderation. Towards the end of the sample, the stochastic volatility of the consumption growth remains low, reflecting the Great Moderation. The real housing price exhibits relative spikes between 1891 and 1951. Shiller (2005) indicates, however, the absence of any major real estate boom before 1940 and associates the observed downward trend to World War I with the great influenza pandemic of 1918-19, the severe recession in 1920-21, and the high unemployment during the 1930s Great Depression. The volatility of the real housing price followed the volatility of consumption, falling from its peak at the beginning of the sample until it stabilized in the early 1950s. After a long period of relative stability, the real housing price experiences new increases in volatility toward the end of the sample, indicating the recent housing boom which started just prior to the financial crisis and Great Recession in the 2000s and its subsequent bust. Further, the stochastic volatility of the real stock market price shows that stock market booms bear virtually no resemblance to housing market booms except in the second half of 2000s where peaks in the housing market followed peaks in the stock market with an average lag of three years. Two periods of relatively high volatility in real stock prices deserve mention. The first peak which occurs during the Great Depression and the second occurs during the 2000s. These relatively high volatilities in the variables confirm the presence of structural breaks mentioned earlier, thus implying the possibility of significant changes in the wealth effects over time. This provides the rationale for using a TVP-VAR where the sources of time variation include both the coefficients and the variance of the innovations.

\subsubsection{Impulse responses}

To compare the evolution of the consumption effect from housing and stock price shocks over 
time, we use the impulse response functions to capture the macroeconomic dynamics based on the estimated VAR model. Figure 3 displays the results of both constant VAR and TVP-VAR models. The standard VAR with time-invariant parameters shows impulse responses whose shapes associate with the average levels of the responses at all points in time over the sample period. Correspondingly, impulse responses from the TVP-VAR model show the responses for each selected horizon (i.e., 1 to 6 years ahead) at all points in time, using the estimated timevarying parameters and showing the magnitude of the responses at each step.

The dynamic responses of consumption to both housing and stock price shocks appear positive in the first year of the constant VAR model, although the positive response to stock price shock does not differ significantly from zero and becomes significantly negative a year later. The positive response of consumption to the housing price shock does prove significantly positive in year one and then falls to nearly zero in all other forecast horizons. Moreover, in terms of magnitude, the price effects generated by both asset categories seem comparable in absolute values, where we contrast the time-varying impulse responses with different magnitudes obtained from the TVP-VAR model. In general, the housing price effect exhibits a positive effect much more frequently than the stock market price effect, which generally exhibits a negative effect over different horizons and over time. In addition, the housing price effect exceeds in absolute value the stock market price effect after 1980. The Tax Reform Act of 1986 tilted the playing field toward borrowing against home equity to finance consumption, as the interest payments on all other forms of credit no longer received a tax deduction. Even without homeowners using their equity as collateral to finance consumption, higher homeowner equity provides a reason to reduce precautionary saving and, hence, increase consumption. Prior to 1980, a positive shock to stock prices results in a 10- to 30-percent decline in consumption at 
short-term horizons against a positive response to house price shocks ranging between 5- to 15percent. The relatively larger effect of changes in the housing price wealth on consumption occurs between 1980 and 2007. In absolute values, the consumption response to a one standard deviation change in the housing price falls between 10 and 25 percent for the 1- and 2-year horizons, while the magnitude of the stock market price effect oscillates between 0 and 10 percent. This relatively lower responsiveness to changes in the housing price before 1980 corresponds to the historical movement in US housing prices, which shows that the housing market boomed from the 1990s.

Although the 1997-2002 asset price boom/bust was driven by both stock and housing markets, the housing price effect dominated the stock market price effect. That is, housing prices continued to rise moderately in 2000-2001 as stock prices fell. Consistent with Benjamin et al. (2004), this suggests that consumption responds more to the moderate increase in the housing price than to the substantial decrease in the stock market price. Different from past episodes, the 2007-2009 boom/bust that occurred in both markets resulted in the decline in both prices. We also observe the resurgence of the bigger and negative effects from the stock market price changes after 2007 for the 6-year horizon, confirming that the magnitude of relative wealth effects may also depend on whether wealth rises or falls (Wilkerson and Williams, 2011).

Studies on the wealth effect on consumption almost exclusively report positive wealth effects. This paper finds that the assumption of parameter constancy may importantly driving those previous findings. The negative impulse responses observed with the stock market price shock over different horizons and over time prove inconsistent with the existing literature. ${ }^{8}$

\footnotetext{
${ }^{8}$ Case, Shiller, and Quigley (2005) and, more recently, Zhou and Carroll (2012) do document a significant positive housing wealth effect and an insignificant negative stock wealth effect in some of their econometric specifications.
} 
Accordingly, besides the negative consumption effect due to the decline in the stock market price, stakeholders draw on their wealth during stock market booms to increase their financial investment and, hence, reduce their consumption. At longer-term horizon, this negative effect dies out, possibly indicating that the positive wealth effect offsets the negative substitution effect in the long run. The plausible implication is that the ultimate purpose of financial investment is to increase future wealth and, hence, future consumption.

We also observe negative responses to changes in the housing price, starting from the third year horizon. We may also ascribe this to the budget constraint and substitution effects. As the house price increases, households who rent face higher costs and reduce their consumption and home owners who plan to buy a home may increase the down payment and future loans, resulting either in a choice of a smaller house or a lower consumption (Ludwig and Sløk, 2001).

\section{Conclusion}

This paper provides empirical evidence of a variation in the relative asset price effects over time. The response of consumption to changes in the stock market price exceeds the effect of the housing price (in absolute terms) before 1980, reflecting the fact that housing market has taken off from 1990s (Shiller, 2005). The larger effect of the housing price on consumption occurs between 1980 and 2007. This sub-period includes the 1997/2002 asset price boom/bust where the housing price continued to rise moderately as the stock market price fell. Thus, consumption response from the modest increase in the housing price in 2000-2001 outweighed the consumption response to the substantial decline in the stock market price. Finally, the cooccurrence of the decline in both forms of asset prices during the 2007-2009 boom/bust caused a bigger effect of the housing price for the first five years while the higher magnitude of the stock market price effect begins from the sixth year onward. These findings suggest that the magnitude 
of the relative asset price effects differs with both time and horizons and also depends on whether asset prices increases or decreases. At longer-term horizons, US consumption reacts more to the decline in the stock market price than to the housing price.

Additionally, we find that changes in the stock market price deliver a negative effect on consumption over different horizons and over time while the direction of the housing price effect varies with both horizon and time. This evidence of negative asset price effect provides further insight on the transmission mechanism from wealth to consumption, hence complementing the almost exclusively reported positive wealth effect in the existing literature. In addition to the ability of the TVP-VAR to track the shape and magnitude of the wealth effect over time, the long length of our dataset captures both the direct and indirect channels through which asset prices may affect consumption. Particularly, our results suggest that the negative substitution effect offsets the aggregate positive wealth effect associated to the stock market over the sample period. This outcome does not appear in the housing market where the aggregate positive wealth effect appears to outweigh the negative budget constraint and substitution effects at most points in time.

\section{References}

Aoki, K., Proudman, J., and Vlieghe, G., 2004. House prices, consumption and monetary policy: a financial accelerator approach. Journal of Financial Intermediation 13, 414-435.

Aye, G. C., Gupta, R., Kaninda, A., Nyakabawo, W. V., and Razak, A., forthcoming. House Price, Stock Price and Consumption in South Africa: A Structural VAR Approach. Corporate Ownership and Control.

Benjamin, J. D., Chinloy, P., and Jud, G. D., 2004. Real estate versus financial wealth in consumption. Journal of Real Estate Finance and Economics 29, 341-354.

Brady, R., and Stimel, D., 2011. How the housing and financial wealth effects have changed over time. Working Paper no. 2011-31, Department of Economics, United States Naval Academy. 
Carroll, C. D., Otsuka, M., and Slacalek, J., 2006. How large is the housing wealth effect? A new Approach. Working Paper No. 12746, National Bureau of Economic Research.

Case, K., Shiller, R., and Quigley, J., 2005. Comparing wealth effects: The stock market versus the housing market. Advances in Macroeconomics 5, 1-32.

Dickey, D., and Fuller, W., 1981. Likelihood ratio statistics for autoregressive time series with a unit root. Econometrica 49, 1057-1072.

Dvornak, N., and Kohler, M., 2007. Housing wealth, stock market wealth and consumption: a panel analysis for Australia. The Economic Record 83, 117-130.

Geweke, J., 1992. Evaluating the accuracy of sampling-based approaches to the calculation of posterior moments. In Bernado, J. M., Berger, J. O., Dawid, A. P., and Smith, A. F. M., (eds), Bayesian Statistics. 4, 169-188, New York: Oxford University Press.

Iacoviello, M., (2011). Housing wealth and consumption. International Finance Discussion Paper 1027, Federal Reserve Board.

Johansen, S. (1988) Statistical analysis of cointegration vectors. Journal of Economic Dynamics and Control, 12, 231-254.

Johansen, S. (1991) Estimation and hypothesis testing of cointegration vectors in Gaussian vector autoregressive models. Econometrica, 59, 1551-1580.

Kishor, K. N., 2007. Does consumption respond more to housing wealth than to financial market wealth? If so, why? Journal of Real Estate Finance and Economics 35, 427-448.

Leonard, J. A., 2010. The impact of the housing market boom and bust on consumption spending. Business Economics 45, 83-93.

Lettau, M., and Luvidson, S. C., 2004. Understanding trend and cycle in asset values: Reevaluating the wealth effect on consumption. American Economic Review 94, 276-299.

Ludwig, A., and Sløk, T., 2001. The impact of stock prices and house prices on consumption in OECD countries. Working Paper no. 01/xx, Research Department, International Monetary Fund.

Mishkin, F., 2007. Housing and the Monetary Transmission Mechanism, Working Paper, Finance and Economic Discussion Series, Federal Reserve Board.

Nakajima, J., 2011. Time-varying parameter VAR model with stochastic volatility: An overview of methodology and empirical applications. Monetary and Economic Studies, 107-142. 
Phillips, P., and Perron, P., 1988. Testing for a unit root in time series regression. Biometrika 75, 335-346.

Poterba, J. M., 2000. Stock market wealth and consumption. Journal of Economic Perspectives 14, 99-118.

Primiceri, G. E., 2005. Time varying structural vector autoregressions and monetary policy. Review of Economic Studies 72, 821-852.

Ng, S., and Perron, P., 2001. Lag lenth selection and the construction of unit root tests with good size and power. Econometrica 69, 1519-1554.

Shiller, R. J., 2005. Irrational exuberance. Princeton University Press, Princeton, New Jersey.

Sousa, R. M., 2008. Financial wealth, housing wealth and consumption. International Research Journal of Finance and Economics 19, 167-191.

Wilkerson, C. R., and Williams, M. D., 2011. Booms and busts in household wealth: implications for tenth District States. Economic Review Second Quarter, 63-86.

Zhou, X. And Carroll, C. D., 2012. Dynamics of wealth and consumption: new and improved measures for U.S. states. The B.E. Journal of Macroeconomics, 12, pages 4. 
Table 1: $\quad$ Posterior estimates results

\begin{tabular}{lccccc}
\hline Parameters & Mean & Std Dev. & 95\% Intervals & Geweke CD & Inefficiency \\
\hline$\left(\boldsymbol{\Sigma}_{\boldsymbol{\beta}}\right)_{\mathbf{1}}$ & 0.239 & 0.059 & {$[0.144,0.375]$} & 0.426 & 22.02 \\
$\left.\boldsymbol{\Sigma}_{\boldsymbol{\beta}}\right)_{\mathbf{2}}$ & 0.165 & 0.041 & {$[0.101,0.261]$} & 0.570 & 19.66 \\
$\left.\boldsymbol{\Sigma}_{\boldsymbol{\alpha}}\right)_{\mathbf{1}}$ & 0.109 & 0.038 & {$[0.053,0.196]$} & 0.569 & 62.50 \\
$\left(\boldsymbol{\Sigma}_{\boldsymbol{\alpha}}\right)_{\boldsymbol{2}}$ & 0.069 & 0.020 & {$[0.040,0.120]$} & 0.697 & 35.53 \\
$\left(\boldsymbol{\Sigma}_{\boldsymbol{h}}\right)_{\mathbf{1}}$ & 0.158 & 0.047 & {$[0.088,0.273]$} & 0.615 & 41.10 \\
$\left(\boldsymbol{\Sigma}_{\boldsymbol{h}}\right)_{\boldsymbol{2}}$ & 0.418 & 0.134 & {$[0.208,0.729]$} & 0.392 & 54.15 \\
\hline \hline
\end{tabular}

Note: The estimates of $\Sigma_{\beta}$ and $\Sigma_{a}$ are multiplied by 100 . 
Figure 1: Posterior estimates for the stochastic volatility of the structural shock
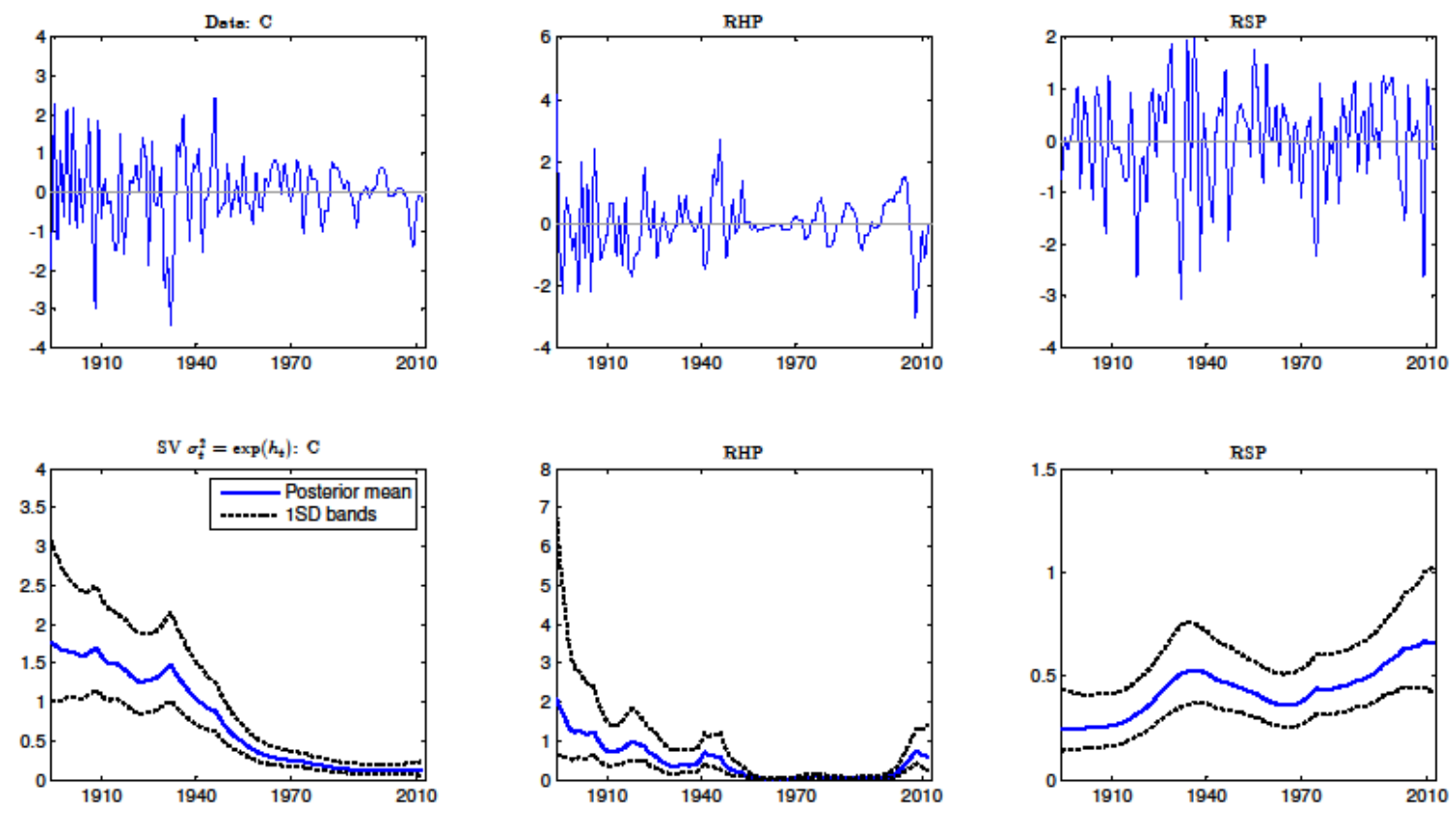
Figure 2: $\quad$ Estimates of the moments and posterior distributions of the model
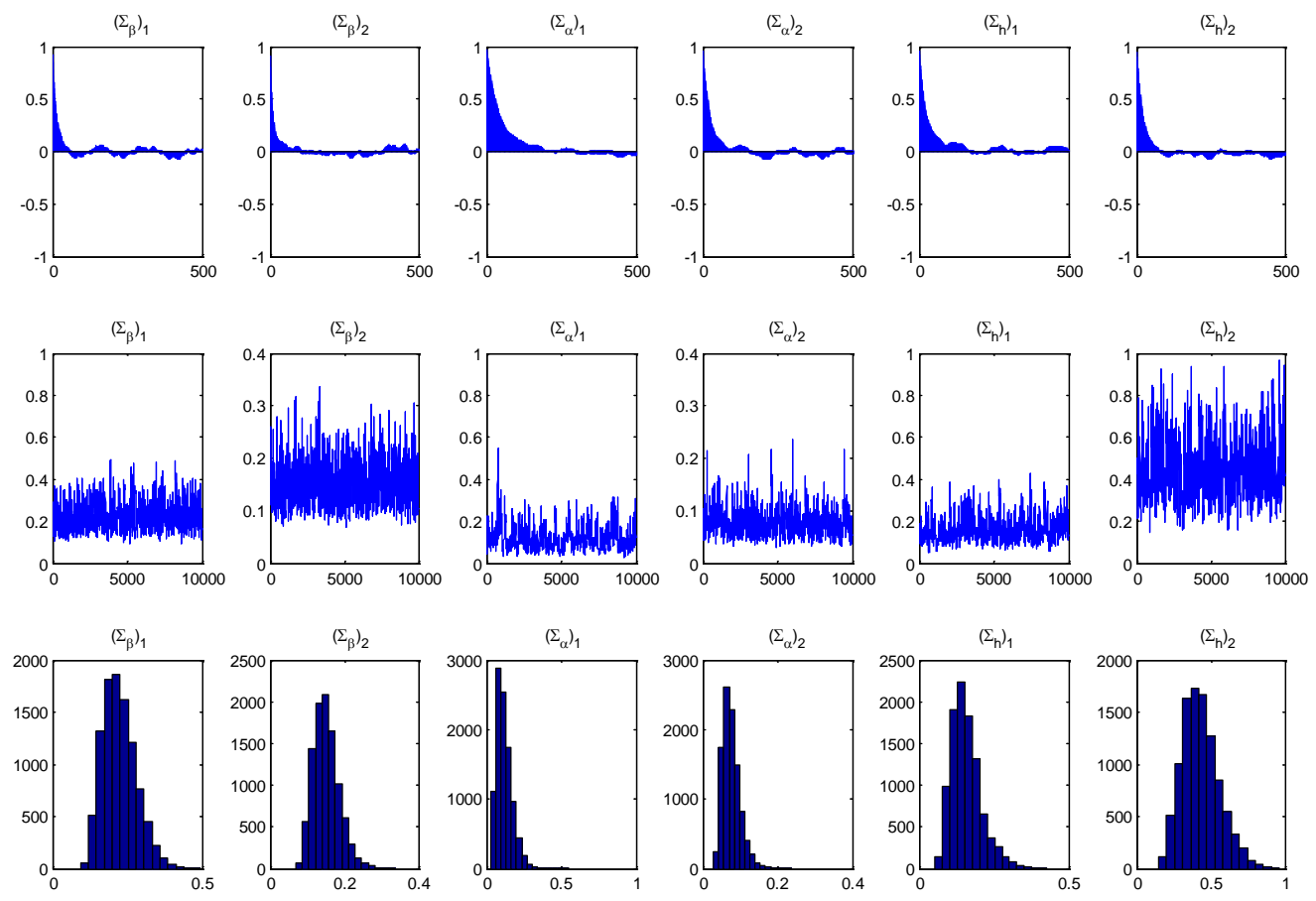

Note: Sample autocorrelations (Top chart), sample paths (middle chart), and posterior densities (bottom chart). The estimate of $\left(\Sigma_{\beta}\right)$ and $\left(\Sigma_{a}\right)$ are multiplied by 100 . 
Figure 3: Impulse responses of the growth rate of consumption to shocks in the growth rates of housing and stock prices:

\section{A: $\quad$ Constant VAR Model}

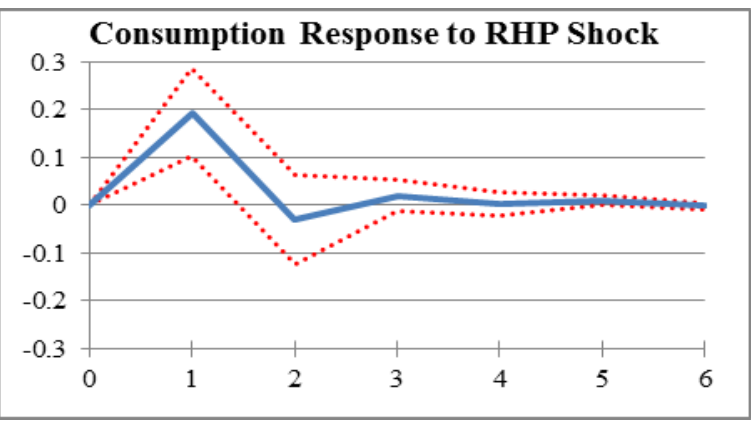

\section{B: $\quad$ TVP-VAR Model}

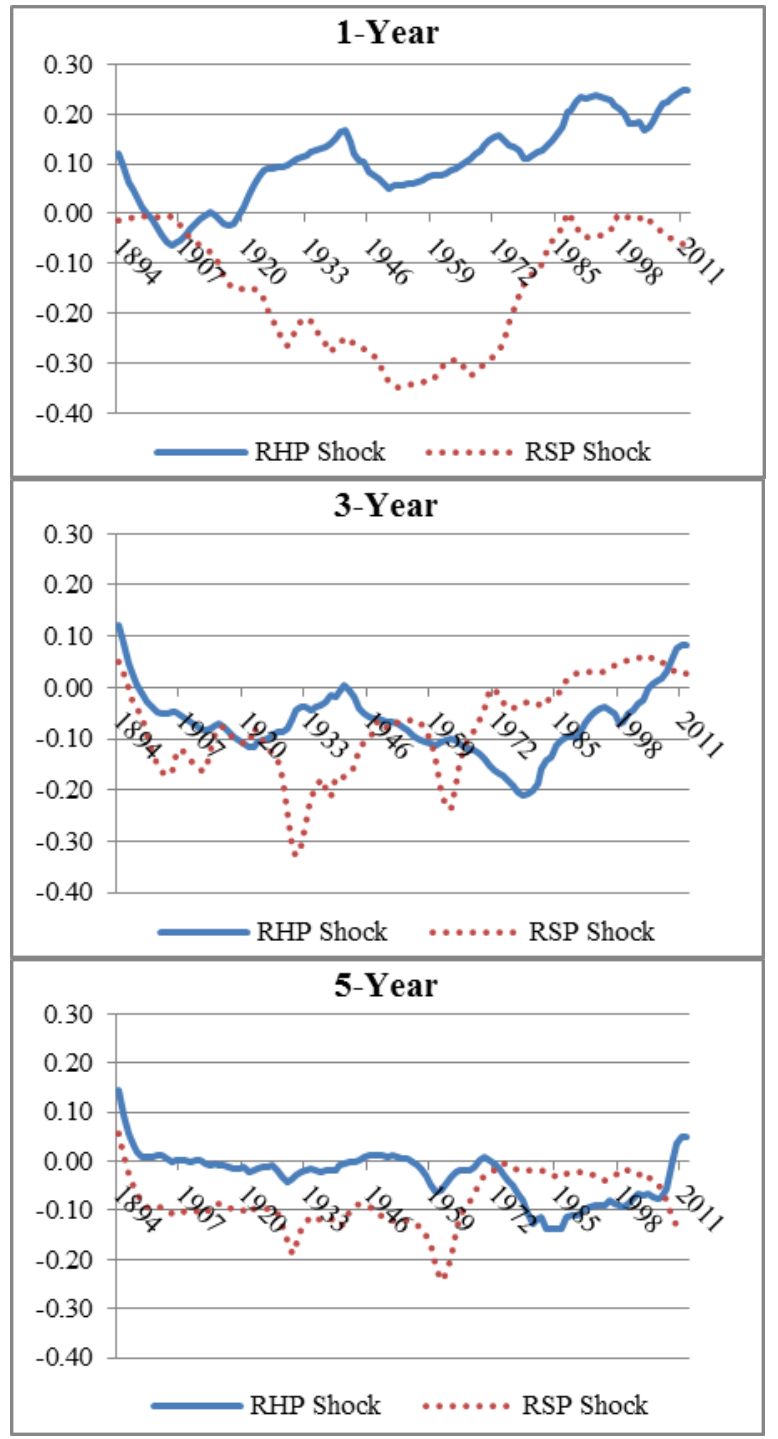

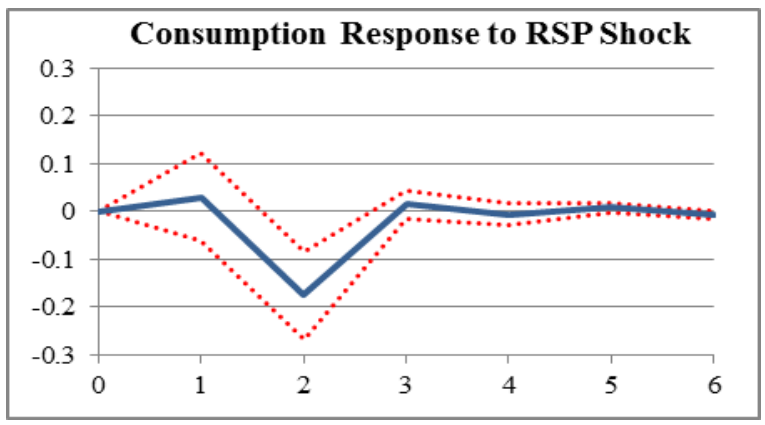

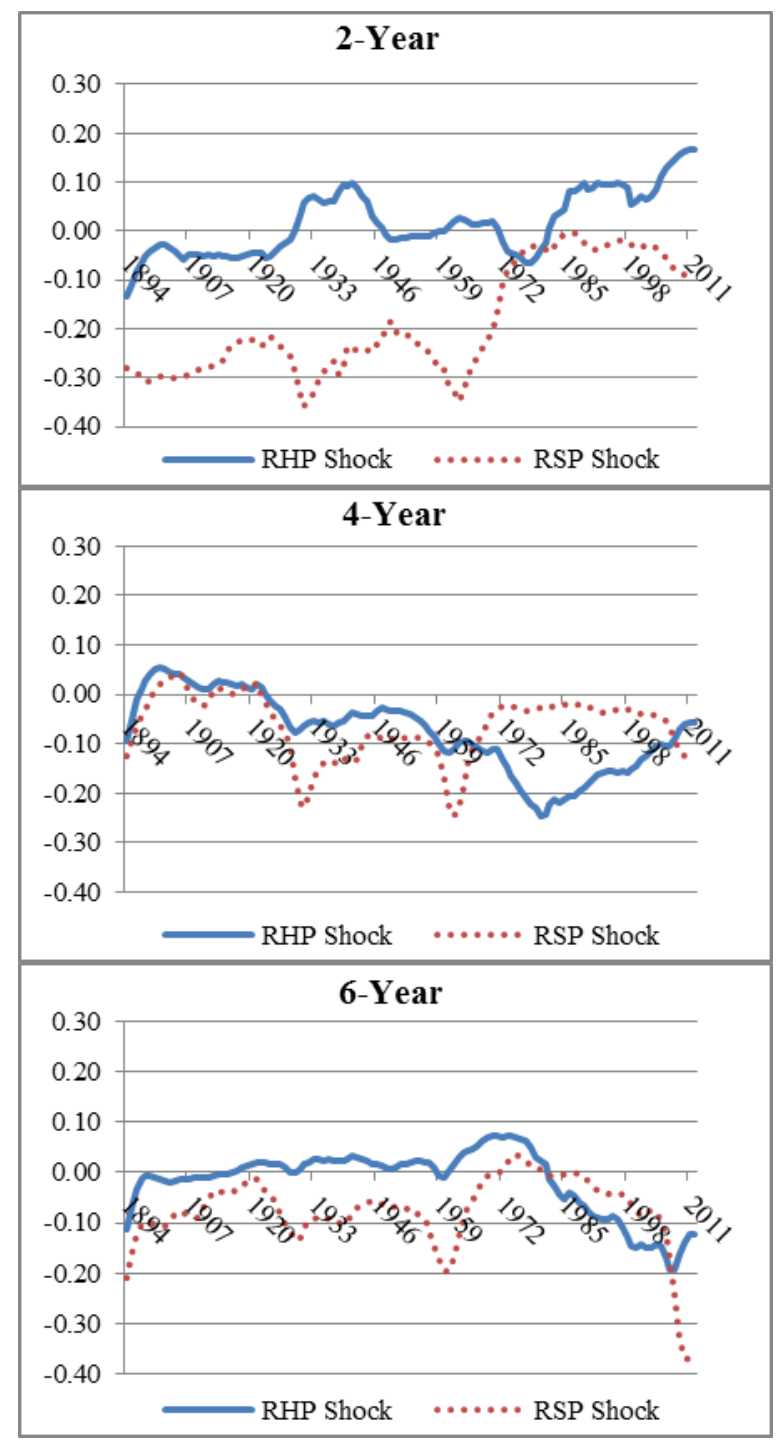


